\title{
Despite Adequate Training, Only Half of Family Physicians Provide Women's Health Care Services
}

\section{Megan Coffman, Elizabeth Wilkinson, and Yalda Jabbarpour}

Access to services related to reproductive and sexual health is critical to the health of women but has been threatened in recent years. Family physicians are trained to provide a range of women's health care services and are an essential part of the health care workforce in rural and underserved areas, where access to these services may be limited. (J Am Board Fam Med 2020;33:186-188.)

Keywords: Contraception, Family Physicians, Health Services Accessibility, Medically Underserved Area, Primary Health Care, Reproductive Health, Residency, Sexual Health, Workforce

Recent literature has shown that despite being well prepared, many recently graduated family physicians do not provide the services they learned in residency. ${ }^{3}$ Our objective was to explore the differences between preparation and the provision of women's health care services among family physicians.

We combined data from 2016 to 2018 American Board of Family Medicine graduate surveys, administered 3 years postresidency graduation, to assess preparation and the current practice of a range of reproductive health procedures consisting of obstetric ultrasound, colposcopy, endometrial biopsy, intrauterine device insertion and removal, implantable long-acting reversible contraception, pregnancy termination, uterine aspiration/dilation and curettage, and maternity care. Keeping only those respondents without missing information for these services, we had a final sample size of 6244 , of which $56.34 \%$ of respondents were women $(\mathrm{n}=3518)$ and $43.67 \%$ were men $(\mathrm{n}=2726)$.

We found that that $97.15 \%$ of recently graduated family physicians feel that their residency

This article was externally peer reviewed.

Submitted 20 August 2019; revised 9 January 2020; accepted 13 January 2020.

From Robert Graham Center, Washington DC (MC, $\mathrm{EW}, \mathrm{YJ})$.

Corresponding author: Megan Coffman, AAFP/Robert Graham Center, Washington DC (E-mail: mcoffman@ aafp.org).

\section{See Related Article on Page 182.}

adequately prepared them at least one of the reproductive health procedures (Table 1). The percentage of recently graduated family physicians who deliver one or more of the reproductive health procedures listed above was $52.75 \%$. Assessing family physicians by gender reveals that $58.98 \%$ of women and $44.72 \%$ of men indicated they provide at least One of the services above as part of their current practice $(P<.001)$.

Despite near-universal rates of reported preparation to deliver the majority of the included sexual and reproductive health procedures, the number of family physicians that currently deliver those services substantially declines in practice (Figure 1).

The delivery of sexual and reproductive health services can be influenced by the scope of practice restrictions, female patient preferences for female physicians, ${ }^{4}$ and other limiting factors that may affect female and male FPs differently.

It has been well-documented that family physicians are limited in practicing obstetric care, and our findings suggest there may also be barriers against the provision of sexual and reproductive care that are not related to inadequate training. ${ }^{1}$ The promotion of policies to increase the proportion of family physicians offering sexual and reproductive care and a greater willingness of practice settings to allow family physicians to perform these services would help meet patients' needs. Given the important role family physicians play in the delivery of health care, particularly in rural and underserved areas where access to reproductive services is already 
Table 1. Reported Preparation and Practice of Sexual or Reproductive Health Services among Recent Family Medicine Residency Graduates by Sex, 2016-2018

\begin{tabular}{|c|c|c|c|c|c|c|}
\hline \multirow[b]{2}{*}{$\begin{array}{l}\text { Women's Sexual and } \\
\text { Reproductive } \\
\text { Health Service }\end{array}$} & \multicolumn{3}{|c|}{$\begin{array}{l}\text { Reported Adequate Preparation for Service } \\
\text { in Residency }\end{array}$} & \multicolumn{3}{|c|}{ Reported Practice Service } \\
\hline & $\begin{array}{c}\text { Female } \\
\text { Physicians } \\
(\mathrm{n}=3518)\end{array}$ & $\begin{array}{c}\text { Male } \\
\text { Physicians } \\
(\mathrm{n}=2726)\end{array}$ & $\begin{array}{c}\text { Total } \\
\text { Physicians } \\
(\mathrm{n}=6244)\end{array}$ & $\begin{array}{c}\text { Female } \\
\text { Physicians } \\
(\mathrm{n}=3518)\end{array}$ & $\begin{array}{c}\text { Male } \\
\text { Physicians } \\
(\mathrm{n}=2726)\end{array}$ & $\begin{array}{c}\text { Total } \\
\text { Physicians } \\
(\mathrm{n}=6244)\end{array}$ \\
\hline \multicolumn{7}{|l|}{ Colposcopy } \\
\hline $\mathrm{n}$ & 2012 & 1517 & 3529 & 612 & 232 & 844 \\
\hline$\%$ & 57.19 & 55.65 & 56.52 & 17.40 & 8.51 & 13.52 \\
\hline \multicolumn{7}{|l|}{ Endometrial biopsy } \\
\hline $\mathrm{n}$ & 2267 & 1648 & 3915 & 1114 & 474 & 1588 \\
\hline$\%$ & 64.44 & 60.45 & 62.70 & 31.67 & 17.39 & 25.43 \\
\hline \multicolumn{7}{|c|}{ IUD insertion and removal } \\
\hline $\mathrm{n}$ & 2798 & 2081 & 4879 & 1712 & 834 & 2546 \\
\hline$\%$ & 79.53 & 76.34 & 78.14 & 48.66 & 30.59 & 40.78 \\
\hline \multicolumn{7}{|c|}{$\begin{array}{l}\text { Implantable long-acting } \\
\text { reversible contraception }\end{array}$} \\
\hline $\mathrm{n}$ & 2441 & 1861 & 4302 & 1597 & 824 & 2421 \\
\hline$\%$ & 69.39 & 68.27 & 68.90 & 45.40 & 30.23 & 38.77 \\
\hline \multicolumn{7}{|l|}{ Maternity care } \\
\hline $\mathrm{n}$ & 3153 & 2470 & 5623 & 1004 & 605 & 1609 \\
\hline$\%$ & 89.62 & 90.61 & 90.05 & 28.54 & 22.19 & 25.77 \\
\hline \multicolumn{7}{|l|}{ Obstetric ultrasound } \\
\hline $\mathrm{n}$ & 1905 & 1675 & 3580 & 552 & 380 & 932 \\
\hline$\%$ & 54.15 & 61.45 & 57.34 & 15.69 & 13.94 & 14.93 \\
\hline \multicolumn{7}{|l|}{ Pregnancy termination } \\
\hline $\mathrm{n}$ & 462 & 354 & 816 & 130 & 55 & 185 \\
\hline$\%$ & 13.13 & 12.99 & 13.07 & 3.70 & 2.02 & 2.96 \\
\hline \multicolumn{7}{|c|}{ Uterine aspiration/D\&C } \\
\hline $\mathrm{n}$ & 532 & 500 & 1032 & 174 & 118 & 292 \\
\hline$\%$ & 15.12 & 18.34 & 16.53 & 4.95 & 4.33 & 4.68 \\
\hline \multicolumn{7}{|c|}{ At least 1 of the above services } \\
\hline $\mathrm{n}$ & 3424 & 2642 & 6066 & 2075 & 1219 & 3294 \\
\hline$\%$ & 97.33 & 96.92 & 97.15 & 58.98 & 44.72 & 52.75 \\
\hline \multicolumn{7}{|l|}{ All of the above services } \\
\hline $\mathrm{n}$ & 163 & 164 & 327 & 43 & 16 & 59 \\
\hline$\%$ & 4.63 & 6.02 & 5.24 & 1.22 & 0.59 & 0.94 \\
\hline
\end{tabular}

IUD, intrauterine device; $\mathrm{D} \& \mathrm{C}$, dilation and curettage.

limited, future research should identify barriers to provision of these services. ${ }^{5}$

To see this article online, please go to: http://jabfm.org/content/ 33/2/186.full.

\section{References}

1. Espey E, Dennis A, Landy U. The importance of access to comprehensive reproductive health care, including abortion: a statement from women's health professional organizations. Am J Obstet Gynecol 2019;220:67-70.
2. Guttmacher Institute. Policy trends in the states, 2017. Available at: https://www.guttmacher.org/article/2018/ 01/policy-trends-states-2017.

3. Weidner AKH, Chen FM. Changes in preparation and practice patterns among new family physicians. Ann Fam Med. 2019;17:46-8.

4. Janssen SM, Lagro-Janssen ALM. Physician's gender, communication style, patient preferences and patient satisfaction in gynecology and obstetrics: a systematic review. Patient Educ Couns. 2012;8: 9221-6.

5. Hung P, Kozhimannil KB, Casey MM, Moscovice IS. Why are obstetric units in rural hospitals closing their doors? Health Serv Res. 2016;51:1546-60. 
Figure 1. Reported preparation and practice of sexual or reproductive health services among recent family medicine residency graduates by gender, 2016 to 2018. Abbreviations: IUD, intrauterine device; D\&C, dilation and curettage.

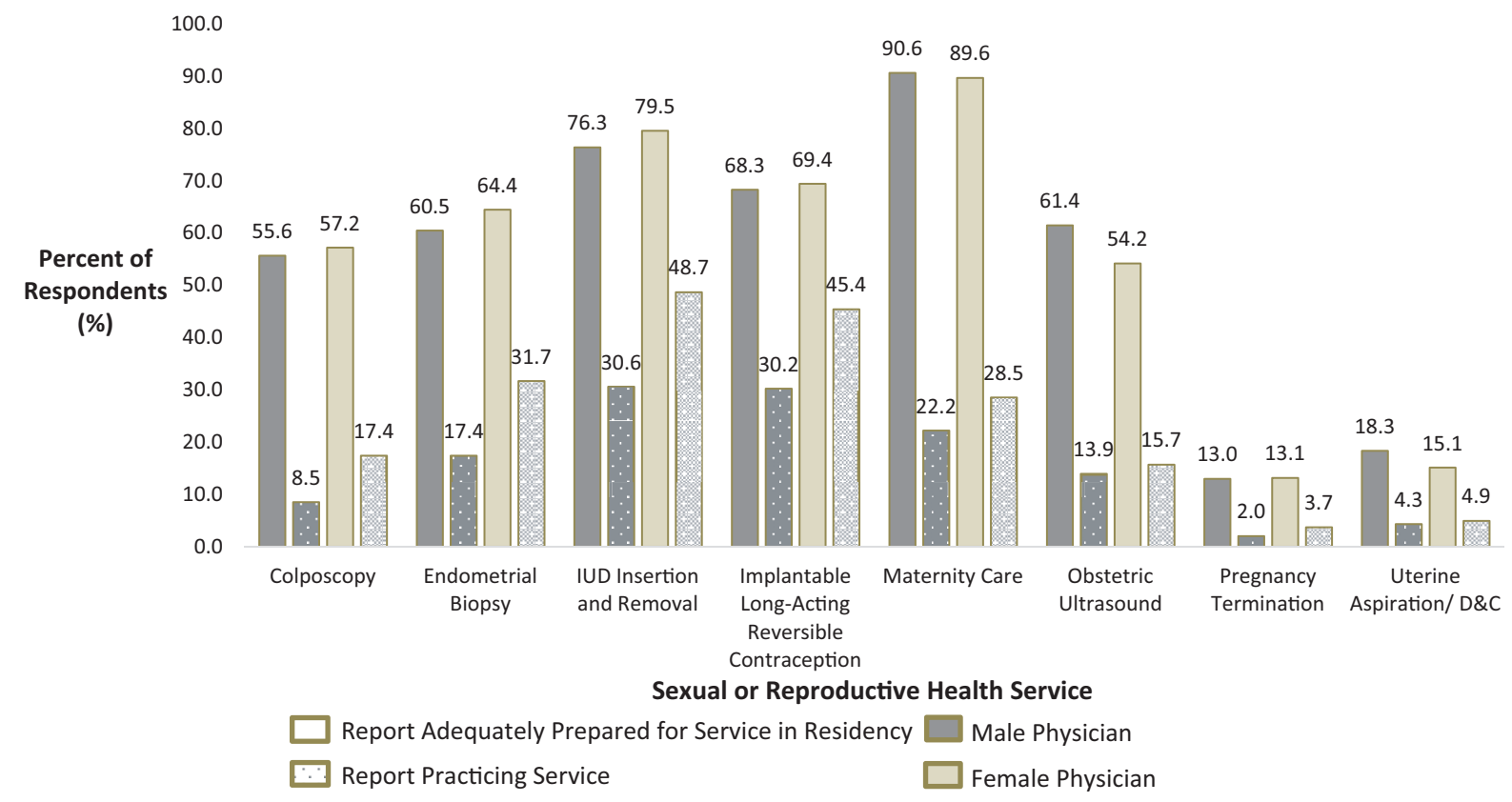

Source: American Board of Family Medicine Graduate Survey, 2016-2018 